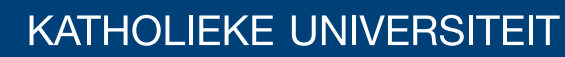 \\ LEUVEN
}

Faculty of Business and Economics

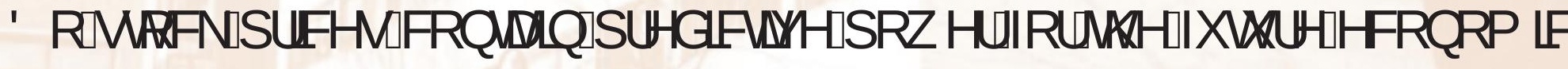

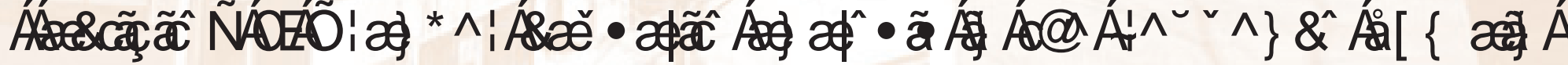

MII\& KUMARSKH\& \&RX[ IDQG]3 HAUS5 HXMHQV

DEPARTMENT OF DECISION SCIENCES AND INFORMATION MANAGEMENT (KBI) 


\title{
Do stock prices contain predictive power for the future economic activity? A Granger causality analysis in the frequency domain
}

\author{
Christophe Croux $^{\mathrm{a}, *}$, Peter Reusens ${ }^{\mathrm{a}}$ \\ ${ }^{a}$ Faculty of Business and Economics, K.U.Leuven, Belgium.
}

\begin{abstract}
This paper investigates the predictive power for future domestic economic activity included in domestic stock prices, using a Granger causality analysis in the frequency domain. We are able to evaluate whether the predictive power is concentrated at the slowly fluctuating components or at the quickly fluctuating components. Using quarterly data for the G-7 countries, we found that the slowly fluctuating components of the stock prices have large predictive power for the future GDP, while this is not the case for the quickly fluctuating components. This finding holds both in a single-country setting and in a multi-country setting. Therefore, macro-economic policy makers could use the slowly fluctuating components of the stock prices to improve their predictions of the future GDP.

Keywords: Frequency Domain, Granger Causality, Gross Domestic Product, Predictive Power, Stock Prices.
\end{abstract}

\footnotetext{
${ }^{*}$ Corresponding author: Faculty of Business and Economics, K.U.Leuven, Naamsestraat 69, B-3000 Leuven Belgium. Tel: +32 16326958 .

Email address: christophe.croux@econ.kuleuven.be (Christophe Croux) 


\section{Introduction}

Recessions in a country have often been preceded by a decline in the domestic stock prices. On the other hand, these stock prices have sometimes given false signals for the future economic activity. For instance, the stock market crash of 1987 was followed by an economic growth instead of an economic decline. Consequently, researchers have spent much attention to the question whether or not the stock prices contain predictive power for the future economic activity.

The theoretical literature on the predictive power of the stock prices for the future economic activity can be categorized into two theories. The first theory focuses on the forward looking behavior of the stock market, whereas the second theory emphasizes the causal effects of the stock prices on the economic activity.

The theory that the stock market is forward looking for the economy is based on the idea that the stock price is the present value of future dividends. As corporate profits are positively correlated with national GDP, it is clear that the future economic activity of a country is related to the future dividends of the country's companies (Fama, 1990; Fischer and Merton, 1984). Hence, an increase in the current expectations about the future economic activity immediately leads to higher stock prices. Thus, this theory explains why current stock prices may have predictive power for the future economic activity. However, several researchers have criticized the theory. Binswanger (2004) argues that the stock prices can deviate from their fundamental values due to the occurrence of speculative bubbles. Moreover, globalization can decrease the link between the domestic stock prices and the domestic economy, as it makes the share price of domestic firms more dependent on foreign sales and the foreign economy (Binswanger, 2004, 2000; Mao and Wu, 2007). Finally, Mahdavi and Sohrabian (1991) mention that variations in the real discount rate and deviations in the linkage between corporate profits and the economic activity can create noise in the prediction of the future economic activity.

The second theory argues that the stock prices can directly affect the future economy through consumption and investment (Kaplan, 2008). In other words, this theory states that the stock prices can cause the future economic activity. A first causal linkage is the effect of the stock prices on consumption, which is established through the wealth effect. This linkage is related to the life cycle hypothesis of savings, which states that people consume a fraction of the present value of their total future income (Ando and Modigliani, 1963). In this context, a rise in the stock prices would increase the wealth of the households, who consequently would elevate their consumption levels. However, several authors state that this wealth effect depends on the distribution of stock ownership across the population (Pearce, 1983). For instance, in the USA, a large part of the stock holdings are possessed by a small group of very wealthy people who have a low propensity to consume out of wealth. Hence, the wealth effect is less important in the USA when compared to countries where the distribution of stock holdings is more widely distributed. In addition, foreign ownership of domestic shares also weakens the wealth effect within a country. Next to the wealth effect, increasing stock prices may impact the consumer confidence and increase consumption (Pearce, 1983). The second 
causal linkage is the effect of the stock prices on investment. The share price of a company can have an impact on its cost of capital, which is a weighted sum of the cost of equity and the cost of debt. As such, an overvaluation of the share price decreases the effective cost of equity (Baker et al., 2003; Fischer and Merton, 1984). Furthermore, high share prices can increase the value of the collateral of companies and a high share price can convey positive information about the value of the company towards lenders. This could increase the perceived creditworthiness of the firm resulting in better loan conditions and a lower cost of debt (Duca, 2007; Morck et al., 1990). Thus, a high share price can lead to a lower cost of capital, which increases the investments made.

In the empirical literature, the concept of Granger causality has been a useful tool to test the predictive power of the stock prices for the future economic activity. This concept, as originally proposed by Granger (1969), has been very widely used in the literature to describe the relationship between variables. Whereas correlation between two variables indicates comovement, Granger causality relates to the idea of incremental predictive power of one time series for forecasting another time series. It is a statistically testable criterion based on the ideas of precedence and predictive power (Yao and Hosoya, 2000). As such, a stationary variable $Y_{t}$ is said to "Granger cause" another stationary variable $X_{t}$, if the past of $Y_{t}$ improves the one period ahead prediction of $X_{t}$ above the information included in the past of $X_{t}$. (Granger, 1969; Lemmens et al., 2008)

The empirical literature has found mixed results regarding the Granger causality relationship between the stock prices and the economic activity. With regard to G-7 countries, the majority of the empirical studies has found significant Granger causality from the stock prices to the economic activity for most countries (Choi et al., 1999; Duca, 2007; Hassapis and Kalyvitis, 2002; Henry et al., 2010; Kim and In, 2003; Lee, 1992; Panopoulou, 2009; Tsouma, 2009). However, Binswanger (2000, 2004) reported that the Granger causality relationship disappeared in the 1980's and 1990's for all G-7 countries (except for inconclusive results for Germany), which he relates to possible speculative behavior in the stock market during that period. Table 2 (see Appendix) provides an overview of these studies for the G-7 countries.

While the current empirical literature has focused on Granger causality from stock prices to economic activity in the time domain, we will go a step further by decomposing the Granger causality in the frequency domain. In this domain, the key idea is that a stationary process can be described as a weighted sum of sinusoidal components with a certain frequency $\omega$. As a result, one can analyze these frequency components separately, e.g. the slowly fluctuating components and the quickly fluctuating components (see Breitung and Candelon, 2006 and Lemmens et al., 2008 among others). This analysis will make it possible to determine whether the predictive power is concentrated at the quickly fluctuating components or at the slowly fluctuating components. As such, instead of computing a single Granger causality measure for the entire relationship, the Granger causality is calculated for each individual frequency component separately. Thus, the strength and/or direction of the Granger causality can be different for each frequency. To the best 
of our knowledge, the analysis of Granger causality from stock prices to economic activity has not yet been explored in the frequency domain. The main part of this paper covers the single-country setting, which is the setting used in the literature. Additionally, we explore the multi-country setting which combines the evidence of Granger causality in all countries under study.

Our paper is organized as follows. Section 2 develops our key hypothesis and describes the data. In the methodology Section 3, we introduce the test procedure for Granger causality in the frequency domain both for a single-country and a multi-country setting. Section 4 presents the empirical results. Finally, Section 5 concludes our findings.

\section{Development of hypotheses and data description}

In our paper, we distinguish between the slowly fluctuating components (low frequencies) and the quickly fluctuating components (high frequencies) of a time series. We define components with a periodicity larger than one year as slowly fluctuating and components with a periodicity less than one year as quickly fluctuating. The strength of the Granger causality from the stock prices to the economic activity is analyzed both for the slowly fluctuating components and for the quickly fluctuating components.

The decomposition of Granger causality in the frequency domain is relevant for macro-economic policy makers. On the one hand, if the predictive power is mainly at the slowly fluctuating components, then taking a priori corrective actions based upon the information contained in the stock prices, would be important. The reason is that the predicted slowdown (or boom) of these slowly fluctuating components of the economic activity would last for a long period of time. On the other hand, if the predictive power is mainly at the quickly fluctuating components, taking corrective actions would be less important. The reason is that stock price movements would only include predictive power for the fast moving (and thus temporary) components of the economic activity.

A priori, we believe that the stock market can forecast the slowly fluctuating components of the future economic activity more accurately than the quickly fluctuating components. Our belief is that the latter consists of the idiosyncratic elements in the economy which are more difficult to predict (Rua, 2010). Consequently, the forward looking stock market (see Section 1) cannot foresee these idiosyncrasies and hence does not include them in the current stock prices. Also the theory that changes in the stock prices cause the future economic activity (see Section 1) is believed to be stronger for the slowly fluctuating components. The reason is that, according to this theory, stock prices movements imply a change in the consumption and investment behavior of individuals and

firms. We expect that people and companies react less to signals of the stock prices which are less persistent in time. In sum, we formulate the following hypothesis: 
Hypothesis. The Granger causality from the stock prices to the economic activity is significant for the slowly fluctuating components, but insignificant for the quickly fluctuating components.

To test this hypothesis, we focus on the G-7 countries. Quarterly data for these countries is obtained from "Thomson Financial Datastream". The sampling period is chosen to be as long as possible for each country. For each country, the sampling period can be found in Table 1 . The number of observations ranges between 78 (Germany) and 187 (USA) observations. A consequence of the quarterly sampling frequency is that the smallest observable periodicity has a period of half a year. ${ }^{1}$ The period of the largest observable periodicity is equal to the length of the sample period, which ranges between 19.5 years (Germany) and 46.75 years (USA).

For each country, a national stock price index is selected in the same way as in Tsouma (2009) (see Table 1). We chose to work with a quarterly average of the daily index values. We believe this is a more representative measure for the entire quarter than the end of quarter values. A real stock price index is then calculated by dividing this quarterly average by the consumer price index (CPI) of the corresponding country. The seasonally adjusted nominal gross domestic product (GDP), deflated by the CPI, is chosen as a measure for the economic activity of each country. Thus, both the stock price index and the GDP are expressed in prices of the domestic currency with as base date the country's CPI base date. Figures 3 and 4 (see Appendix) show the time plots of respectively GDP and the stock price index in levels.

Table 1: Choice for the sampling period, the stock price index and the base date of the consumer price index (CPI) for each G-7 country.

\begin{tabular}{|llll|}
\hline Country & Sampling period & Stock price index & CPI base date \\
\hline USA & 1964Q1-2010Q2 & S\&P 500 & $1982-1984$ \\
\hline Japan & 1980Q1-2010Q2 & Nikkei 225 & 2005 \\
\hline UK & 1969Q1-2010Q2 & FTSE all shares & 2005 \\
\hline Italy & 1980Q1-2010Q2 & FTSE MIB & 1995 \\
\hline France & 1988Q1-2010Q2 & SBF 250 & 1998 \\
\hline Canada & 1969Q1-2010Q2 & S\&P/TSX Composite & 2002 \\
\hline Germany & 1991Q1-2010Q2 & DAX 30 & 2005 \\
\hline
\end{tabular}

\section{Methodology}

The concept of Granger causality in the frequency domain was originally proposed by Clive Granger in 1969 (Granger, 1969). Subsequently, Geweke (1982) proposed a measure for this Granger causality in the frequency domain. Several test procedures for Granger causality at a given frequency have been developed for this Geweke measure. Geweke (1982) proposed a Wald-test that imposes

\footnotetext{
${ }^{1}$ This smallest periodicity is called the Nyquist frequency. For details, see Hamilton (1994).
} 
linear restrictions on the coefficient parameters. This test procedure was further elaborated by Breitung and Candelon (2006). Yao and Hosoya (2000) have developed an alternative Wald-type test which is based on non-linear restrictions on the VAR parameters. Finally, Seth (2010) discusses tests based on bootstrap and permutation resampling techniques. In this paper, we use the test procedure of Breitung and Candelon (2006).

Testing for Granger causality in the frequency domain has been applied to a wide range of research questions. Gronwald (2009) has studied the causal relationship between the oil price and several other macroeconomic and financial market variables. The causal effects of money, output and the output gap on the inflation rate have been analyzed by Assenmacher-Wesche and Gerlach (2008a,b). Lemmens et al. (2008) have studied the predictive value of production expectation surveys in the frequency domain. Breitung and Candelon (2006) have analyzed at which frequencies the interest rate spread has predictive power for the real economic growth. The causal relationship between tax and government expenditures has been analyzed in the frequency domain by Koren and Stiassny (1998). Nishiyama (1997) applied the Geweke framework to the causality relationship between export sector growth and non-export sector growth. McGarvey (1991) used an adapted version of Geweke's framework to test the neutrality of money hypothesis that money growth has no causal effect on the relative price changes. Next to economic applications, Granger causality techniques in the frequency domain have been extensively used to study the causal interactions in neural data (e.g. Ding et al., 2006).

This methodology section is organized as follows. We consider both the single-country and the multi-country setting. We discuss the model assumptions and outline a test procedure for Granger causality in the frequency domain.

\subsection{Single-country setting}

We review the test procedure for Granger causality in the frequency domain of Breitung and Candelon (2006). In this single-country setting, we want to test the Granger causality of a univariate series $Y_{t}$ for another univariate series $X_{t}$ within the same country. In our setting, $Y_{t}$ is the growth rate of a national stock price index and $X_{t}$ is the domestic GDP growth rate.

Let $X_{t}$ and $Y_{t}$ be two centered stationary time series. We assume a finite-order vector autoregressive (VAR) representation of the form

$$
\Theta(L)\left(\begin{array}{c}
X_{t} \\
Y_{t}
\end{array}\right)=\left(\begin{array}{cc}
\Theta_{11}(L) & \Theta_{12}(L) \\
\Theta_{21}(L) & \Theta_{22}(L)
\end{array}\right)\left(\begin{array}{c}
X_{t} \\
Y_{t}
\end{array}\right)=\left(\begin{array}{c}
\epsilon_{1 t} \\
\epsilon_{2 t}
\end{array}\right)
$$

where $\Theta(L)=I-\Theta_{1} L-\Theta_{2} L^{2}-\ldots-\Theta_{p} L^{p}$ is a $2 \times 2$ lag polynomial of order $p$ with $L^{j} X_{t}=X_{t-j}$

and $L^{j} Y_{t}=Y_{t-j}$. The error vector $\epsilon_{t}=\left(\epsilon_{1 t} \epsilon_{2 t}\right)^{\prime}$ is assumed to be multivariate white noise with $\mathrm{E}\left(\epsilon_{t}\right)=0$ and $\mathrm{E}\left(\epsilon_{t} \epsilon_{t}^{\prime}\right)=\Sigma$, where $\Sigma$ is positive definite and symmetric. Note that there is no intercept as we work with centered data for ease of exposition. 
We start again from the VAR model (1). As $\Sigma$ is positive definite and symmetric, a Cholesky decomposition $G^{\prime} G=\Sigma^{-1}$ exists, where $G$ is a lower triangular matrix and $G^{\prime}$ is an upper triangular matrix. Using this Cholesky decomposition, the MA representation of the system can be expressed as

$$
\left(\begin{array}{c}
X_{t} \\
Y_{t}
\end{array}\right)=\Psi(L)\left(\begin{array}{l}
\eta_{1 t} \\
\eta_{2 t}
\end{array}\right)=\left(\begin{array}{ll}
\Psi_{11}(L) & \Psi_{12}(L) \\
\Psi_{21}(L) & \Psi_{22}(L)
\end{array}\right)\left(\begin{array}{l}
\eta_{1 t} \\
\eta_{2 t}
\end{array}\right),
$$

where $\Psi(L)=\Theta(L)^{-1} G^{-1}$ and $\left(\eta_{1 t} \eta_{2 t}\right)^{\prime}=G\left(\epsilon_{1 t} \epsilon_{2 t}\right)^{\prime}$, so that $\operatorname{cov}\left(\eta_{1 t}, \eta_{2 t}\right)=0$ and $\operatorname{var}\left(\eta_{1 t}\right)=$ $\operatorname{var}\left(\eta_{2 t}\right)=1$. From (2), it is clear that $X_{t}$ can be described as a sum of two uncorrelated MA processes. In particular, it is the sum of an intrinsic component driven by past shocks in $X_{t}$ and a component containing the predictive power of the variable $Y_{t}$. We can determine the predictive power of $Y_{t}$ at each frequency $\omega$ by comparing the predictive component of the spectrum with the intrinsic component at that frequency. It is said that $Y_{t}$ does not "Granger cause" $X_{t}$ at frequency $\omega$ if the predictive component of the spectrum of $X_{t}$ at frequency $\omega$ is zero. This motivates the measure of causality suggested by Geweke (1982) and defined as

$$
M_{y \rightarrow x}(\omega)=\log \left[1+\frac{\left|\Psi_{12}\left(e^{-i \omega}\right)\right|^{2}}{\left|\Psi_{11}\left(e^{-i \omega}\right)\right|^{2}}\right]
$$

This measure of causality is the ratio of the total spectrum divided by the intrinsic component of the spectrum. It is expressed in this way so that $M_{y \rightarrow x}(\omega)=0$ if $\left|\Psi_{12}\left(e^{-i \omega}\right)\right|=0$. Hence, the equation $\left|\Psi_{12}\left(e^{-i \omega}\right)\right|=0$ provides a condition for no Granger causality at frequency $\omega$.

Breitung and Candelon (2006) have simplified the above condition for no Granger causality at frequency $\omega$ to a set of linear restrictions on the coefficients of the first component of the VAR model (1)

$$
X_{t}=\sum_{j=1}^{p} \Theta_{11, j} X_{t-j}+\sum_{j=1}^{p} \Theta_{12, j} Y_{t-j}+\epsilon_{1 t},
$$

where $\Theta_{11, j}$ and $\Theta_{12, j}$ are the coefficients of the lag polynomials $\Theta_{11}(L)$ and $\Theta_{12}(L)$. A necessary and sufficient set of conditions for no Granger causality at frequency $\omega$ is given by

$$
\left\{\begin{array}{l}
\sum_{j=1}^{p} \Theta_{12, j} \cos (j \omega)=0 \\
\sum_{j=1}^{p} \Theta_{12, j} \sin (j \omega)=0 .
\end{array}\right.
$$

The linear restrictions (5) on the coefficients can be tested by a standard F-test. The resulting F-statistic is approximately distributed as $F(2, T-2 p)$, where 2 is the number of restrictions and $T$ is the number of observations used to estimate the VAR model of order $p$. Equivalently, the linear restrictions (5) can be tested by an incremental R-squared measure test, quantifying the proportion of explained variability of $X_{t}$ lost due to the imposition of the two restrictions in (5). It is defined as 
the difference between the R-squared measure $R^{2}$ of the unrestricted model (4) and the R-squared measure $R_{*}^{2}$ of the model estimated under the restrictions (5):

$$
\text { Incremental } R^{2}=R^{2}-R_{*}^{2} \text {. }
$$

This incremental R-squared measure can be interpreted as the strength of the Granger causality from $Y_{t}$ to $X_{t}$ at frequency $\omega$ and always lies between zero and one. By plotting the incremental Rsquared for the frequencies between 0 and $\pi$, one can visualize the strength of the Granger causality over the entire frequency domain $(0, \pi)$. The null hypothesis of no Granger causality at frequency $\omega$ is rejected at level $\alpha$ if

$$
\text { IncrementalR } R^{2}>F_{(2, T-2 p, 1-\alpha)} \frac{2}{T-2 p}\left(1-R^{2}\right),
$$

where $F_{(2, T-2 p, 1-\alpha)}$ is the $\alpha$ upper critical value of the F-distribution with 2 and $T-2 p$ degrees of freedom. (Greene, 2002, page 102)

Finally, let us briefly discuss the choice of the lag order $p$ in the VAR equation (1). We will always choose $p \geq 3$, since for values $p=1$ and $p=2$, the F-statistic is constant for all frequencies $\omega$. Lemmens et al. (2008) show in a simulation study that the Bayesian Information Criterion (BIC) performs well for testing Granger causality in the frequency domain. Hence, we use the BIC for determining the optimal lag length $p$ of the VAR model. The BIC is defined as

$$
B I C(p)=\ln \operatorname{det} \widehat{\Sigma}+\frac{\ln T}{T} 4 p,
$$

where $\widehat{\Sigma}$ is the covariance matrix of the residuals of the estimated $\operatorname{VAR}(p)$ model. Note that the number of regression parameters equals $4 p$. The selected lag length is then the value of $p \geq 3$ minimizing (8).

\subsection{Multi-country setting}

In this section, we propose a multi-country test for the Granger causality in the frequency domain, that captures the predictive power of $Y_{t}$ for forecasting $X_{t}$ over the G-7 countries. Combining information across $G$ countries yields a more powerful test.

Consider the seemingly unrelated regression (SUR) equations

$$
X_{i, t}=\sum_{j=1}^{p} \alpha_{i, j} X_{i, t-j}+\sum_{j=1}^{p} \beta_{i, j} Y_{i, t-j}+\epsilon_{i, t} \quad \text { for } i=1, \ldots, G
$$

where $X_{i, t}$ and $Y_{i, t}$ are the variables of country $i$ at time $t, \epsilon_{i, t}$ is the error term of country $i$ at time $t, p$ is the lag length and $G$ is the number of countries under study. Whereas the error terms are assumed to be uncorrelated across time, they can be contemporaneously correlated, since unobserved factors that influence the economic activity are often linked across countries. The 
estimation of the SUR model is performed by the feasible generalized least squares estimator method (FGLS).

Within the SUR model (9), we test a set of linear restrictions on the parameters of equation (9). To be specific, there is no Granger causality from $Y_{t}$ to $X_{t}$ at frequency $\omega$ if

$$
\begin{cases}\sum_{j=1}^{p} \beta_{i, j} \cos (j \omega)=0 & \text { for } i=1, \ldots, G \\ \sum_{j=1}^{p} \beta_{i, j} \sin (j \omega)=0 & \text { for } i=1, \ldots, G\end{cases}
$$

Similar to the single-country setting, we define an incremental R-squared

$$
\text { Incremental } R^{2}=R^{2}-R_{*}^{2},
$$

where $R^{2}$ and $R_{*}^{2}$ are the McElroy R-squared values of respectively the unrestricted and the restricted SUR model (McElroy, 1977). This McElroy value is the traditional R-squared of the SUR model in stacked form and transformed towards i.i.d. error terms (see Buse, 1979 and Greene, 2002, page 345). It is extensively used as a goodness of fit measure in a SUR setting (e.g. Fraquelli et al., 2004). The null hypothesis of no Granger causality at frequency $\omega$ in all countries is rejected at level $\alpha$ if

$$
\text { Incremental } R^{2}>F_{(2 G, G(T-2 p), 1-\alpha)} \frac{2 G}{G(T-2 p)}\left(1-R^{2}\right),
$$

where $F_{(2 G, G(T-2 p), 1-\alpha)}$ is the $\alpha$ critical value of the $\mathrm{F}$ distribution. The number of restrictions is $2 G$, the total number of observations is $G T$ and $2 G p$ is the total number of estimated coefficients.

\section{Results}

We start with an analysis of the predictive power of the stock prices for the economic activity for every single G-7 country. To get stationarity, we take GDP and the stock price index in log differences. Hence $X_{t}$ stands for GDP growth rate and $Y_{t}$ for the growth rate of the stock price index. ADF-tests confirm that $X_{t}$ and $Y_{t}$ are stationary in almost all countries. Also, the null hypothesis of no cointegration between the logged GDP series and the logged stock price index series cannot be rejected. The order of the VAR model is selected according to the BIC criterion (see section 3.1). Next, the assumption of multivariate white noise of the error vector in the VAR equation (1) is verified for each country: heteroscedasticity is tested by a multivariate arch test and serial correlation is tested by a Portmanteau test. For all countries except UK, the assumption of multivariate white noise error terms is not rejected. ${ }^{2}$

\footnotetext{
${ }^{2}$ For UK, the null hypothesis of no heteroscedasticity is rejected. However, as visual inspection of the time plot of the residuals of the VAR model did not show large heteroscedasticity, we consider it to comply with the model assumptions.
} 
Figure 1 presents the incremental R-squared test for Granger causality in the frequency domain for all frequencies $\omega$ in $(0, \pi)$. The frequencies are expressed as angular quarterly frequencies $\omega$. These angular quarterly frequency can be translated into a periodicity of $S$ years by $S=$ $\pi /(2 \omega)$. We consider the slowly fluctuating components to have a periodicity larger than one year, which corresponds to the angular quarterly frequencies smaller than 1.5. The quickly fluctuating components have a periodicity smaller than one year, which corresponds to an angular quarterly frequency larger than 1.5. For each G-7 country, the incremental R-squared, as defined in Section 3.1 , is shown together with its $5 \%$ critical value (see equation (7)). This incremental R-squared is a measure for the strength of the Granger causality from the stock price index growth to the GDP growth at the given frequency $\omega$. Thus, the higher this incremental R-squared at frequency $\omega$, the more predictive power for the future GDP growth is contained in the stock price index growth at that frequency $\omega$. If the value is higher than the $5 \%$ critical value, the stock price index is said to significantly "Granger cause" the GDP growth at frequency $\omega$.

Figure 1 shows clearly that for all countries, the incremental R-squared at the low frequencies is significant. This means there is significant Granger causality from the slowly fluctuating components of the stock price index growth to the corresponding slowly fluctuating components of the GDP growth. In other words, the stock price index growth contains predictive power for the future GDP growth at the low frequencies. On the other hand, the strength of the Granger causality is much smaller at the high frequencies: the incremental R-squared at these high frequencies does not reach the level of significance in most countries. This means that the quickly fluctuating components of the stock price index growth cannot predict the corresponding quickly fluctuating components of the future GDP growth. In some countries however, the Granger causality at these high frequencies is found to be significant. This is the case for the UK and Canada and to a lesser extent the USA. Still, for these countries as well, the Granger causality at the low frequencies is more important than at the high frequencies. In conclusion, the results are in line with our hypothesis of Section 2, which stated that the Granger causality of the stock price index growth for the GDP growth is significant at the low frequencies and insignificant at the high frequencies. These results are also in line with Kim and In (2003) who found, using wavelet analysis, that the stock prices have predictive power for the industrial production in the USA at the lower frequencies (periodicities larger than sixteen months). ${ }^{3}$ Whereas the wavelet analysis can handle non-stationary time series, the frequency domain approach is more simple and focuses on stationary time series.

The average incremental R-squared at the low frequencies is about 0.08 . This means that, with regard to the slowly fluctuating components of the time series, about $8 \%$ of the variation of the GDP growth can be explained by the past of the stock price index growth, in addition to the variance already explained by the past of the GDP growth. It should be noted that the average

\footnotetext{
${ }^{3}$ Kim and In (2003) also found significant Granger causality at the very short frequencies (periodicity of two to eight months), which is in line with our results for the USA.
} 

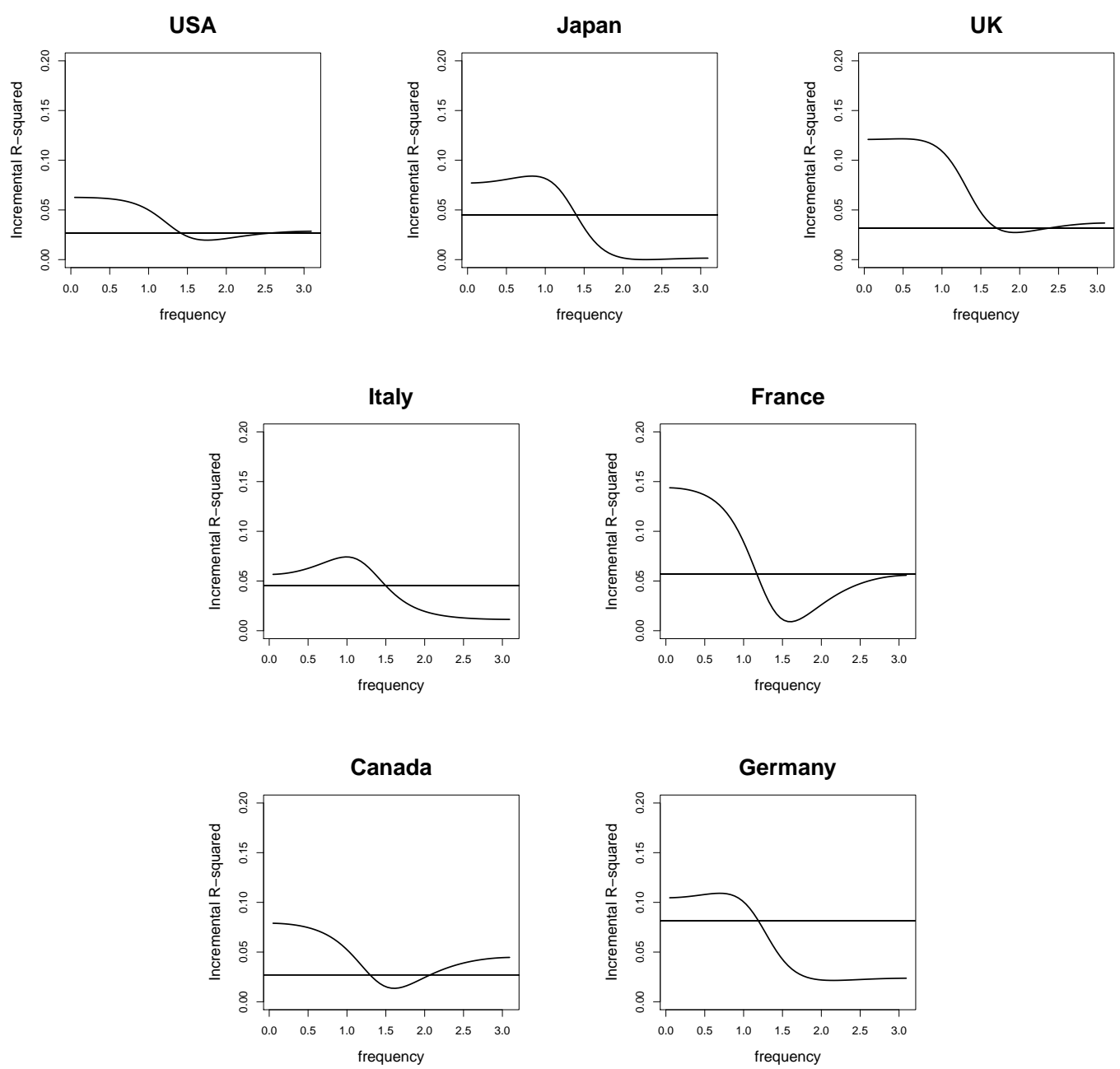

Figure 1: Granger causality test for the G-7 countries. The incremental R-squared value is presented as a function of the frequencies $\omega$ in $(0, \pi)$. The horizontal line represents the $5 \%$ critical value of the null hypothesis test of no Granger causality at frequency $\omega$. 
incremental R-squared at the low frequencies is the highest (about 0.10) for France and the lowest (about 0.05 ) for the USA. This might indicate that the stock prices in France have more predictive power than in the USA. Rather, we would interpret our results in a more general way: we found that the stock price index growth has a significant predictive power for the future GDP growth at the low frequencies and that these results are valid for all countries under study.

Figure 2 presents the multi-country test for Granger causality in the frequency domain for all frequencies $\omega$ in $(0, \pi) .{ }^{4}$ The incremental R-squared value as defined in equation (11) is plotted versus the frequency. This value is a measure for the strength of the Granger causality of the stock price index growth for the GDP growth combining evidence of predictive power of the G-7 countries. Figure 2 shows that the incremental R-squared is significant for the slowly fluctuating components and insignificant for the quickly fluctuating components. Thus, this multi-country test confirms the empirical results of the single-country analysis; whereas the slowly fluctuating components of the stock price index growth have significant predictive power for the corresponding components of the future GDP growth, this is not the case for the quickly fluctuating components.

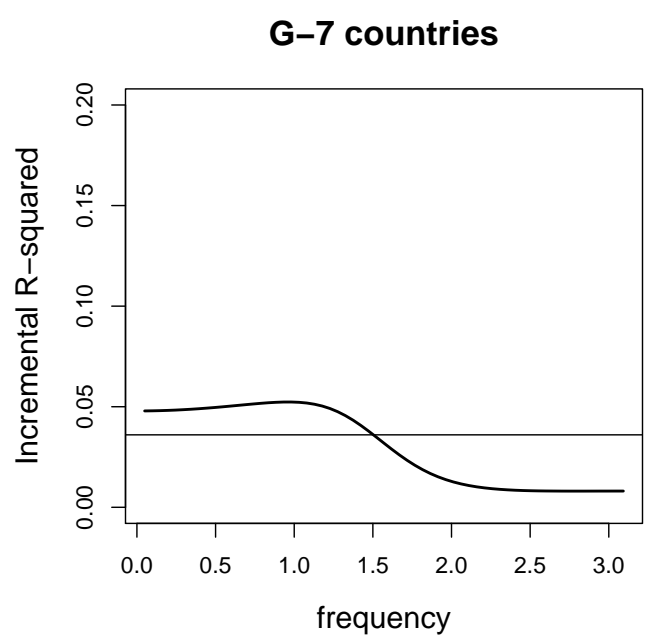

Figure 2: Multi-country Granger causality test for the G-7 countries. The incremental R-squared value is presented as a function of the frequencies $\omega$ in $(0, \pi)$. The horizontal line represents the $5 \%$ critical value of the null hypothesis test of no Granger causality at frequency $\omega$.

\footnotetext{
${ }^{4}$ Data from the period 1991Q1-2010Q2 are used for the multi-country analysis. The lag length of the SUR model is chosen to be three, which is also the optimal lag length for all the single-country VAR models.
} 


\section{Conclusion}

In this paper, we have investigated the predictive power for the future domestic economic activity that is contained in the domestic stock prices. Consistent with the current literature on the topic, we have used the concept of Granger causality to evaluate this predictive power. The main contribution of our research is that we have decomposed the Granger causality in the frequency domain. This analysis makes it possible to evaluate whether the predictive power is concentrated at the slowly fluctuating components or at the quickly fluctuating components. For this purpose, the Geweke (1982) test procedure has been applied both in a single-country setting and in a multi-country setting. The procedure is easy to implement (R-code is available on the author's website).

We focused on quarterly data for the G-7 countries. A national stock price index and domestic GDP are chosen as measures for the domestic stock prices and domestic economic activity, respectively. Both the single-country and multi-country analysis have demonstrated that there is significant Granger causality from the stock price index growth to the GDP growth at the slowly fluctuating components. In contrast, this Granger causality is much weaker at the quickly fluctuating components. Therefore, the predictive power of the stock prices for the future GDP is predominantly present at the low frequencies. In particular, the slowly fluctuating components of past stock price growth rates can explain on average about $8 \%$ of the variation of the slowly fluctuating components of the GDP growth, in addition to the variation that is already included in the past of the slowly fluctuating components of the GDP growth.

An alternative way to study Granger causality in the frequency domain was proposed by Pierce (1979). A comparison between this test procedure and the test procedure of Geweke (1982) was made in Lemmens et al. (2008). As a robustness check, we have performed the Pierce test procedure, yielding similar outcomes (results are available upon request).

The insights in this paper are relevant for macro-economic policy makers. They could use the stock prices to improve their predictions for the slowly fluctuating components of the GDP growth. These predictions will allow them to anticipate the future economic activity by taking stabilizing actions in advance. The fact that the stock prices are an instantaneously available and free source of information enhances the value of the stock prices as a leading indicator.

One limitation of our study is that our empirical study cannot discriminate between the channels behind the predictive power of the stock prices for the economic activity. Our Granger causality framework only allowed to determine the strength of the total predictive power, which is in line with other empirical research on the issue. In the introduction, we briefly discussed two main channels for the predictive power: on the one hand, a channel that emphasizes the forward looking behavior of the stock market and on the other hand, a channel that focuses on the causal effects of the stock prices on the economic activity. Future research could look at the disentanglement of the predictive power of the stock prices for the economic growth into these two channels. This knowledge would be of great value to policy makers. In particular, if future studies would find that the causal effect of the stock prices on the future economic activity is important, there might be 
room for policy makers to intervene in the stock market in order to stabilize (i.e. to directly affect) the economy. Taking measures that prevent extreme instabilities in stock prices could then be part of such a stabilization policy (Duca, 2007). Of course, it remains the question whether governments are allowed to actively intervene in the stock market.

This paper is the first to study the Granger causality from the stock prices to the economic activity in the frequency domain. The analysis was performed for seven countries both in a singlecountry setting and in a multi-country setting. We believe that our findings are generalizable to other markets that have a well developed stock market and large GDP. As such, we have repeated the study for Australia, yielding similar results.

\section{References}

Ando, A. and Modigliani, F. (1963). The "life cycle" hypothesis of saving: aggregate implications and tests. The American Economic Review, 53(1), 55-84.

Assenmacher-Wesche, K. and Gerlach, S. (2008a). Interpreting euro area inflation at high and low frequencies. European Economic Review, 52(6), $964-986$.

Assenmacher-Wesche, K. and Gerlach, S. (2008b). Money growth, output gaps and inflation at low and high frequency: spectral estimates for Switzerland. Journal of Economic Dynamics and Control, 32(2), $411-435$.

Baker, M., Stein, J., and Wurgler, J. (2003). When does the market matter? Stock prices and the investment of equity-dependent firms. Quarterly Journal of Economics, 118(3), 969-1005.

Binswanger, M. (2000). Stock returns and real activity: is there still a connection? Applied Financial Economics, 10(4), 379-387.

Binswanger, M. (2004). Stock returns and real activity in the G-7 countries: did the relationship change during the 1980s? The Quarterly Review of Economics and Finance, 44(2), 237-252.

Breitung, J. and Candelon, B. (2006). Testing for short- and long-run causality: a frequency-domain approach. Journal of Econometrics, 132(2), 363-378.

Buse, A. (1979). Goodness-of-fit in the seemingly unrelated regressions model: a generalization. Journal of Econometrics, 10(1), 109-113.

Choi, J., Hauser, S., and Kopecky, K. (1999). Does the stock market predict real activity? Time series evidence from the G-7 countries. Journal of Banking \& Finance, 23(12), 1771-1792.

Ding, M., Chen, Y., and Bressler, S. L. (2006). Granger causality: basic theory and application to neuroscience. In Handbook of Time Series Analysis, pages 437-460. Wiley-VCH Verlag. 
Duca, G. (2007). The relationship between the stock market and the economy: experience from international financial markets. Bank of Valletta Review, 36, 1-12.

Fama, E. (1990). Stock returns, expected returns, and real activity. Journal of Finance, 45(4), 1089-1108.

Fischer, S. and Merton, R. C. (1984). Macroeconomics and finance: the role of the stock market. Carnegie-Rochester Conference Series on Public Policy, 21, 57 - 108.

Fraquelli, G., Piacenza, M., and Vannoni, D. (2004). Scope and scale economies in multi-utilities: evidence from gas, water and electricity combinations. Applied Economics, 36(18), 2045-2057.

Geweke, J. (1982). Measurement of linear dependence and feedback between multiple time series. Journal of the American Statistical Association, 77(378), 304-324.

Granger, C. (1969). Investigating causal relations by econometric models and cross-spectral methods. Econometrica, 37(3), 424-438.

Greene, W. H. (2002). Econometric Analysis. Prentice Hall, New Jersey, 5th edition.

Gronwald, M. (2009). Reconsidering the macroeconomics of the oil price in Germany: testing for causality in the frequency domain. Empirical Economics, 36(2), 441-453.

Hamilton, J. D. (1994). Time Series Analysis. Princeton University Press, 1 edition.

Hassapis, C. and Kalyvitis, S. (2002). Investigating the links between growth and real stock price changes with empirical evidence from the G-7 economies. The Quarterly Review of Economics and Finance, 42(3), $543-575$.

Henry, O., Olekalns, N., and Shields, K. (2010). Sign and phase asymmetry: news, economic activity and the stock market. Journal of Macroeconomics, 32(4), 1083-1100.

Kaplan, M. (2008). The impact of stock market on real economic activity: evidence from Turkey. Journal of Applied Sciences, 8(2), 374-378.

Kim, S. and In, F. (2003). The relationship between financial variables and real economic activity: evidence from spectral and wavelet analyses. Studies in Nonlinear Dynamics and Econometrics, $7(4), 1-16$.

Koren, S. and Stiassny, A. (1998). Tax and spend, or spend and tax? An international study. Journal of Policy Modeling, 20(2), 163-191.

Lee, B. (1992). Causal relations among stock returns, interest-rates, real activity, and inflation. Journal of Finance, 47(4), 1591-1603. 
Lemmens, A., Croux, C., and Dekimpe, M. G. (2008). Measuring and testing Granger causality over the spectrum: an application to European production expectation surveys. International Journal of Forecasting, 24(3), 414-431.

Mahdavi, S. and Sohrabian, A. (1991). The link between the rate of growth of stock prices and the rate of growth of GNP in the United States: a Granger causality test. The American Economist, 35(2), 41-48.

Mao, Y. and Wu, R. (2007). Does the stock market act as a signal for real activity? Evidence from Australia. Economic Papers, 26(2), 180-192.

McElroy, M. B. (1977). Goodness of fit for seemingly unrelated regressions : Glahn's r2y.x and Hooper's r2. Journal of Econometrics, 6(3), 381-387.

McGarvey, M. (1991). The neutrality properties of competing relative price models: tests using linear feedback. Journal of Business 83 Economic Statistics, 9(1), 15-25.

Morck, R., Shleifer, A., and Vishny, R. (1990). The stock-market and investment - is the market a sideshow. Brookings Papers on Economic Activity, 1990(2), 157-215.

Nishiyama, Y. (1997). Exports' contribution to economic growth: empirical evidence for California, Massachusetts, and Texas, using employment data. Journal of Regional Science, 37(1), 99-125.

Panopoulou, E. (2009). Financial variables and euro area growth: a non-parametric causality analysis. Economic Modelling, 26(6), 1414-1419.

Pearce, D. (1983). Stock prices and the economy. Economic Review, 3, 7-22.

Pierce, D. (1979). R 2 measures for time series. Journal of the American Statistical Association, 74(368), 901-910.

Rua, A. (2010). Measuring comovement in the time-frequency space. Journal of Macroeconomics, 32(2), 685-691.

Seth, A. K. (2010). A matlab toolbox for granger causal connectivity analysis. Journal of Neuroscience Methods, 186(2), 262 - 273.

Tsouma, E. (2009). Stock returns and economic activity in mature and emerging markets. The Quarterly Review of Economics and Finance, 49(2), 668 - 685.

Yao, F. and Hosoya, Y. (2000). Inference on one-way effect and evidence in Japanese macroeconomic data. Journal of Econometrics, 98(2), 225 - 255. 


\section{Appendix}

Table 2: Overview of the empirical literature on Granger causality tests in the G-7 countries. For each study, the sample period, the sampling frequency, the measure for economic activity and the outcome of the Granger causality test is shown. The sampling frequency can be monthly (M), quarterly (Q) or annually (A). The measure for economic activity is Gross Domestic Product (GDP), Gross National Product (GNP) or Industrial Production (IP). The outcome of the Granger causality test can be significant (Y), not significant (N) or inconclusive (I).

\begin{tabular}{|c|c|c|c|c|c|}
\hline Country & Paper & $\begin{array}{l}\text { Sampling } \\
\text { period }\end{array}$ & $\begin{array}{l}\text { Sampling } \\
\text { frequency }\end{array}$ & $\begin{array}{l}\text { Economic } \\
\text { activity } \\
\text { measure }\end{array}$ & $\begin{array}{l}\text { Granger } \\
\text { causality }\end{array}$ \\
\hline \multirow[t]{7}{*}{ USA } & Binswanger (2000) & $1984-1995$ & $\mathrm{M}, \mathrm{Q}$ & IP & $\mathrm{N}$ \\
\hline & Choi et al. (1999) & $1957-1996$ & $\mathrm{M}, \mathrm{Q}, \mathrm{A}$ & IP & $\mathrm{Y}$ \\
\hline & Duca (2007) & $1957-2004$ & $\mathrm{Q}$ & GDP & $\mathrm{Y}$ \\
\hline & Hassapis and Kalyvitis (2002) & $1960-1997$ & $\mathrm{Q}, \mathrm{A}$ & IP & $\mathrm{Y}$ \\
\hline & Henry et al. (2010) & $1946-2004$ & M & IP & $\mathrm{Y}$ \\
\hline & Lee (1992) & $1947-1987$ & M & IP & $\mathrm{Y}$ \\
\hline & Tsouma (2009) & 1991-2006 & M & IP & $\mathrm{Y}$ \\
\hline \multirow[t]{5}{*}{ UK } & Binswanger (2004) & $1983-1999$ & $\mathrm{Q}$ & GDP & $\mathrm{N}$ \\
\hline & Choi et al. (1999) & $1957-1996$ & $\mathrm{M}, \mathrm{Q}, \mathrm{A}$ & IP & $\mathrm{Y}$ \\
\hline & Duca $(2007)$ & $1970-2004$ & $\mathrm{Q}$ & GDP & $\mathrm{Y}$ \\
\hline & Hassapis and Kalyvitis (2002) & $1960-1997$ & $\mathrm{Q}, \mathrm{A}$ & IP & $\mathrm{Y}$ \\
\hline & Tsouma (2009) & 1991-2006 & $\mathrm{M}$ & IP & $\mathrm{Y}$ \\
\hline \multirow[t]{5}{*}{ Japan } & Binswanger (2004) & 1983-1999 & Q & GDP & $\mathrm{N}$ \\
\hline & Choi et al. (1999) & $1957-1996$ & $\mathrm{M}, \mathrm{Q}, \mathrm{A}$ & IP & $\mathrm{Y}$ \\
\hline & Duca $(2007)$ & $1957-2004$ & Q & GDP & $\mathrm{Y}$ \\
\hline & Hassapis and Kalyvitis (2002) & $1957-1997$ & $\mathrm{Q}, \mathrm{A}$ & IP & $\mathrm{Y}$ \\
\hline & Tsouma (2009) & 1991-2006 & M & IP & $\mathrm{Y}$ \\
\hline \multirow[t]{4}{*}{ Canada } & Binswanger (2004) & 1983-1999 & $\mathrm{Q}$ & GDP & $\mathrm{N}$ \\
\hline & Choi et al. (1999) & $1957-1996$ & $\mathrm{M}, \mathrm{Q}, \mathrm{A}$ & IP & $\mathrm{Y}$ \\
\hline & Hassapis and Kalyvitis (2002) & $1957-1997$ & $\mathrm{Q}, \mathrm{A}$ & IP & $\mathrm{Y}$ \\
\hline & Tsouma (2009) & $1991-2006$ & M & IP & $\mathrm{Y}$ \\
\hline \multirow[t]{6}{*}{ France } & Binswanger (2004) & $1983-1999$ & Q & GDP & $\mathrm{N}$ \\
\hline & Choi et al. (1999) & $1957-1996$ & $\mathrm{Q}$ & IP & $\mathrm{Y}$ \\
\hline & Duca $(2007)$ & $1970-2004$ & $\mathrm{Q}$ & GDP & $\mathrm{Y}$ \\
\hline & Hassapis and Kalyvitis (2002) & $1950-1996$ & $\mathrm{Q}, \mathrm{A}$ & IP & $\mathrm{N}$ \\
\hline & Panopoulou (2009) & $1988-2005$ & M & IP & $\mathrm{Y}$ \\
\hline & Tsouma (2009) & 1991-2006 & M & IP & $\mathrm{Y}$ \\
\hline \multirow[t]{5}{*}{ Italy } & Binswanger (2004) & 1983-1999 & $\mathrm{Q}$ & GDP & $\mathrm{N}$ \\
\hline & Choi et al. (1999) & $1997-1996$ & $\mathrm{M}, \mathrm{Q}, \mathrm{A}$ & IP & $\mathrm{N}$ \\
\hline & Hassapis and Kalyvitis (2002) & $1949-1997$ & $\mathrm{Q}, \mathrm{A}$ & IP & $\mathrm{N}$ \\
\hline & Panopoulou (2009) & $1988-2005$ & M & IP & $\mathrm{Y}$ \\
\hline & Tsouma (2009) & $1991-2006$ & M & IP & $\mathrm{Y}$ \\
\hline \multirow[t]{6}{*}{ Germany } & Binswanger (2004) & 1983-1999 & $\mathrm{Q}$ & GDP & $\mathrm{I}$ \\
\hline & Choi et al. (1999) & $1957-1996$ & $\mathrm{M}, \mathrm{Q}, \mathrm{A}$ & IP & $\mathrm{Y}$ \\
\hline & Duca (2007) & $1970-2004$ & $\mathrm{Q}$ & GDP & $\mathrm{N}$ \\
\hline & Hassapis and Kalyvitis (2002) & 1971-1996 & $\mathrm{Q}, \mathrm{A}$ & IP & $\mathrm{N}$ \\
\hline & Panopoulou (2009) & $1988-2005$ & $\mathrm{M}$ & IP & $\mathrm{Y}$ \\
\hline & Tsouma (2009) & $1991-2006$ & M & IP & $\mathrm{Y}$ \\
\hline
\end{tabular}





Figure 3: Time plot of GDP in levels for the G-7 countries. The GDP is the seasonally adjusted nominal gross domestic product (GDP), deflated by the CPI. The unit is in millions (for Japan, UK, Italy, France and Canada) or billions (for USA, Germany) of the domestic currency.
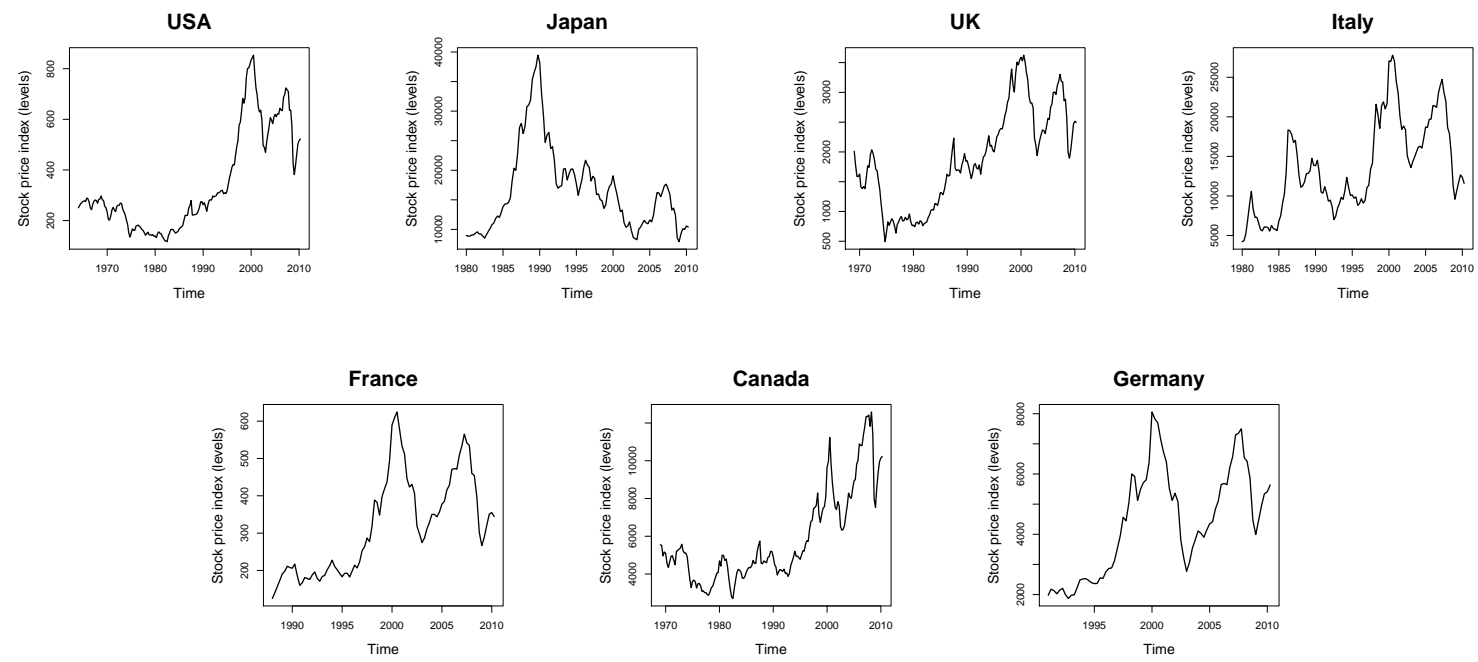

Figure 4: Time plot of the stock price index in levels for the G-7 countries. The stock price index shown in this figure is the quarterly average of the daily index values deflated by the consumer price index (CPI) of each country. 